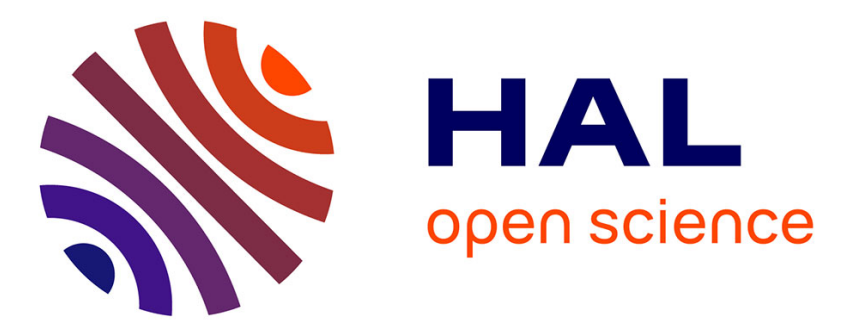

\title{
Ontology-Based Framework to Design a Collaborative Human-Robotic Workcell
}

\author{
Dario Antonelli, Giulia Bruno
}

\section{To cite this version:}

Dario Antonelli, Giulia Bruno. Ontology-Based Framework to Design a Collaborative Human-Robotic Workcell. 18th Working Conference on Virtual Enterprises (PROVE), Sep 2017, Vicenza, Italy. pp.167-174, 10.1007/978-3-319-65151-4_16 . hal-01674858

\section{HAL Id: hal-01674858 https://hal.inria.fr/hal-01674858}

Submitted on 3 Jan 2018

HAL is a multi-disciplinary open access archive for the deposit and dissemination of scientific research documents, whether they are published or not. The documents may come from teaching and research institutions in France or abroad, or from public or private research centers.
L'archive ouverte pluridisciplinaire HAL, est destinée au dépôt et à la diffusion de documents scientifiques de niveau recherche, publiés ou non, émanant des établissements d'enseignement et de recherche français ou étrangers, des laboratoires publics ou privés.

\section{(c)(1)}

Distributed under a Creative Commons Attribution| 4.0 International License 


\title{
Ontology-based Framework to Design a Collaborative Human-Robotic Workcell
}

\author{
Dario Antonelli and Giulia Bruno \\ Politecnico di Torino, Department of Management and Production Engineering, \\ Corso Duca degli Abruzzi 24, 10129 Torino, Italy \\ \{dario.antonelli, giulia.bruno\}@polito.it
}

\begin{abstract}
Exploiting the collaboration between human and robots is a fundamental target for industrial Cyber-Physical Systems. Several studies have already addressed the evaluation of collaborative robotic cells, especially in automotive industry. Feasible tasks assignment to workers and robots were proposed in a few use-cases. However, previous studies start from an existing configuration of the collaborative assembly cell. Due to the moderate diffusion of collaborative robotic applications in the industry, it would be better to define a method orienting the design of a new instances of collaborative cells, by taking into account the different classifications of collaboration deriving by the new ISO 15066 standard. The classification depends on the kind of information that must be made available within the cell, and the possible methods of acquisition and communication of such information. This knowledge base will be represented in the form of ontology, as an extension of the CORA (Core Ontologies for Robotics and Automation) ontology, by IEEE Robotics and Automation Society. By adopting this ontology, it will be possible to support the design of new collaborative cell. An industrial case-study will prove the efficacy of the proposed method.
\end{abstract}

Keywords: Collaborative robots, cyber physical systems, ontology.

\section{Introduction}

The design of collaborative environments where robots can work side by side with human operators for the execution of complex industrial tasks is having an increasing interest from both academics and robot manufacturers. In a survey on innovative flexible approaches to automotive assembly technologies, considerable importance is given to cooperation among humans and robots [1]. For example, some complex assembly procedures require both precise handling and other assembly operations, such as inserting fasteners and connecting wire harnesses. Some of these tasks require the precision and speed of automation, while others benefit from the dexterity and intelligence of human operators.

Human-Robot Collaboration (HRC) brings benefits to industrial applications in terms of speed, efficiency, better quality of the production and better quality of the workplace (ergonomic) [2]. However, as far as now, robotic automation was rarely applied in small batch productions, due to the variety of products and of variable 
production schedules [3]. The workplace organization leans towards flexibility where manual systems are advantaged. Now, several robot manufacturers are designing special robot architectures, named collaborative robots, allowing the human workers to execute their tasks in the same workplace as the robots, e.g., KUKA LBR [4] and ABB YuMi [5]. However, these robots have limitations in terms of payload, velocity, and strength that prevent their use in several industrial contexts. Some of these limits are related to the necessity of respecting the Technical Specifications ISO 15066 in order to assure human worker safety.

Differently from such architectures, present study focuses on the subset of HRC that exploits standard industrial robots and allows for a safe interaction with the robot, paying a reasonable fee in reduced flexibility. The field of study is the industrial manual and automatic assembly by welding. Small factories usually already have robotic welding cells next to their manual workstations. The aim of this work is to show that it is possible to redesign existing industrial robotic cells for executing a number of collaborative actions, respecting safety requirements.

The rest of the paper is organized as follows. Section 2 revises the state of the art in literature. Section 3 describes the two ontologies necessary in this study, used to classify the kind of information that must be made available within the cell, and the possible methods of acquisition and communication of such information. In Section 4, the design and setup of a HRC working cell is described, specifically for an industrial use case. Finally Section 5 draws conclusions and states future works.

\section{Related Works}

The collaborative execution of manufacturing tasks between humans and robots aims to improve the efficiency of industrial processes, for an high adaptability and robustness of the cell Several works are present in literature that address the evaluation of robotic cells, especially in automotive industry $[6,7]$.

Some efforts have been devoted to investigate the safety of human-robot collaboration [8,9], and also the problem of define the optimal assignment of tasks between workers and robots was studied in some use-cases [10,11]. Other problems investigated in literature address the psychological acceptation of the robot as a reliable team member $[12,13]$.

Some studies are related to the reduction of programming time of robots by exploiting Programming by Demonstration or Learning by Demonstration techniques $[14,15,16]$. Even if several human capabilities cannot be fully replaced by robots, it is possible to achieve a solution by combining the capabilities of both. Moving the collaborative robot from laboratory demonstrations to current production cells arises new orders of issues that have not been adequately considered in the past.

What's missing is a solid methodology to configure a HRC cell, based on the manufacturing process under consideration and the kind of collaboration to implement. 


\section{HRC Ontologies}

Ontologies plays a fundamental role in knowledge management because they formally specifies the key concepts, properties, relationships, and axioms of a given domain [17].Two ontologies are necessary in this study. The first one, named CCORA, is an extension of a standard ontology for robotics and automation (CORA) by adding concepts related to collaborative cells. The second one, named MPRO, is a manufacturing process ontology, which contains concepts related to manufacturing processes and related machines, tools and parameters.

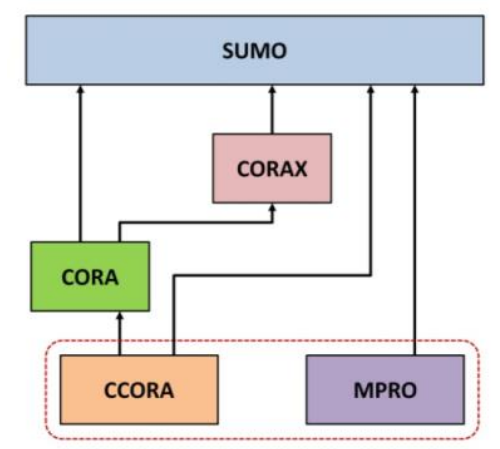

Fig. 1. Relationships between the two defined ontologies (CCORA and MPRO) with respect to previous ontologies SUMO, CORA and CORAX.

The relationships between CCORA and MPRO with the other existing ontologies in the domain is represented in Fig.1. The Ontologies for Robotics and Automation Working Group (ORA WG) defined a core ontology for robotics and automation (CORA), which specifies the general concepts in this context [18]. CORA extends SUMO, the Suggested Upper Merged Ontology, which is an open source upper ontology, widely used in several domains [19]. Between CORA and SUMO, there is the CORAX ontology, which represents concepts and relations commonly found in subdomains but that are too general to be included in CORA [20]. We further extended the CORA ontology in the Collaborative CORA (CCORA) by inserting the concepts related to human-robot collaboration. CCORA inherits from both CORA and SUMO, because some CCORA entities are specifications of more general SUMO concepts. The MPRO ontology cover the knowledge related to manufacturing operations, thus is inherits directly from the SUMO concepts.

\subsection{Collaborative CORA (CCORA) Ontology}

The most general SUMO category is Entity, given as a disjoint partition of Physical and Abstract entities. The first one represents entities with spatio-temporal extension, while the second one is for entities that do not need have spatio-temporal extension. 
Both entities are further specialized: Physical into Object and Process, while Abstract into Quantity, Attribute, SetOrClass, Relation and Proposition. SUMO has a total of more than 500 entities, covering a broad spectrum of concepts.

The CORAX ontology defines concepts that are too general to be in CORA, which cover aspects of reality that are necessary for modelling, but are not explicitly or completely covered by SUMO. Examples of CORAX entities are physical environment, interaction, artificial system, processing device, robot motion, human robot communication, robot robot communication.

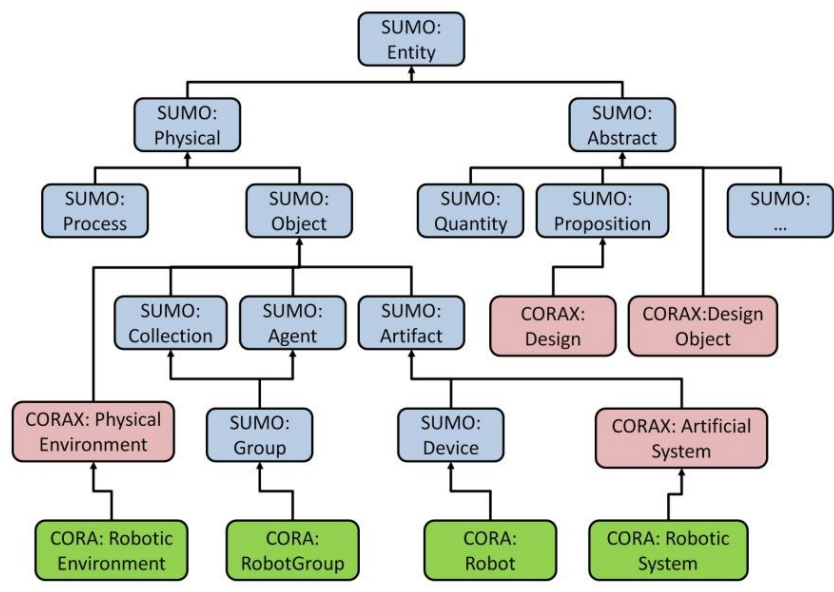

Fig. 2. Relationships among concepts of SUMO, CORAX and CORA.

CORA focuses on defining a robot, along with the specification of other related entities. The entities defined in the CORA ontology are Robot part, Robot interface, Robot group, Robotic system (further divided into Single Robotic System and Collective Robotic System) and Robotic environment. The relationships among concepts of SUMO, CORAX and CORA are represented in Fig.2.

We further extended the CORA ontology in the Collaborative CORA (CCORA) by inserting the concepts related to human-robot collaboration, as shown in Fig. 3. We defined a collaborative robotic system an entity formed by robots, human workers, and a series of devices. Particularly, four kinds of devices are need: observing devices, pointing devices, gripping devices and holding devices. A collaborative robotic environment, i.e., a collaborative cell, is an environment equipped with a collaborative robotic system.

Three types of collaborative environments exist, the spatial collaboration environment, the temporal collaboration environment, and the spatiotemporal coloration environment. Depending on the kind of collaborative environment, different devices are needed. For example, in the case of a spatial collaboration, where humans and robots work in the same space but in different times, observing devices are mandatory (e.g., laser scanner) to reveal the human presence, to grant that the human worker is not in the cell while the robot is working.

CCORA also extends the SUMO Process with the transport processes, which are not covered by the MPRO ontology. 


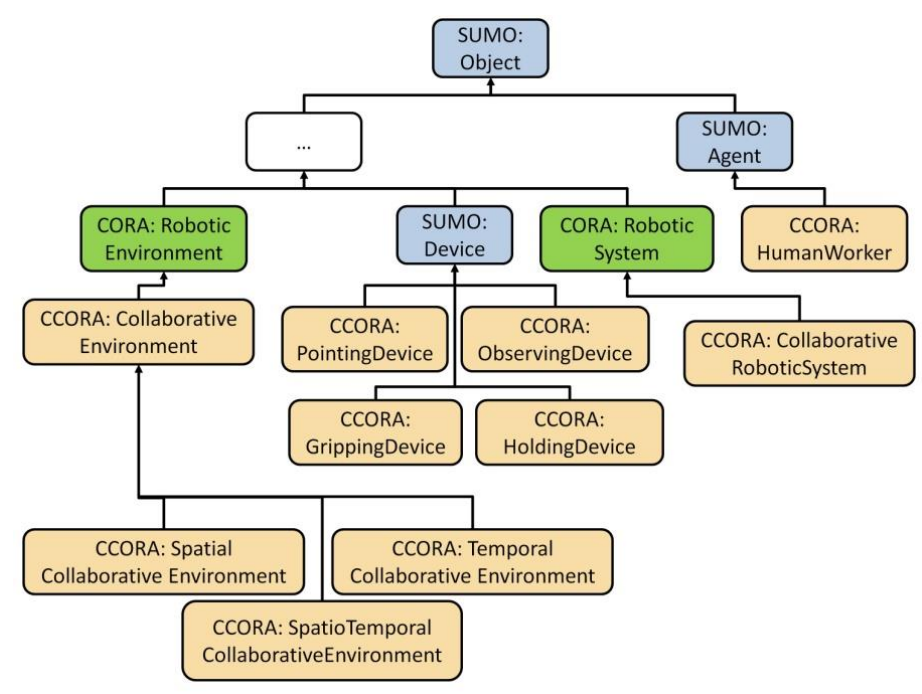

Fig. 3. Relationships among concepts of CCORA, SUMO and CORA.

\subsection{Manufacturing Process (MPRO) Ontology}

The MPRO ontology cover the knowledge related to manufacturing operations. The main classes of the MPRO ontology are Manufacturing process, Machine, Tool and Parameter [21]. A portion of the MPRO ontology related to the SUMO ontology is shown in Fig.4.

Assembly operations are further divided in Permanent joining processes and Mechanical fastening. Permanent joining processes are Welding, Brazing and soldering, and Adhesive bonding. Welding processes are further divided between Fusion welding and Solid state welding. To Fusion welding belong Arc Welding, Resistance Welding, Oxyfuel gas welding, and others.

Tools are the elements that are used during processes or directly perform the work on the workpiece. For example, Welding tools are used in different welding processes and include Welding molds, Solid state tools, and Fusion welding tools. Fusion welding tools are mostly related with Electrodes, which can be Consumables, if they are consumed during the process or Non-consumables. Consumables electrodes are Coated electrodes, Electrogas welding electrode, Flux cored electrodes, Wire electrodes, and GMAW guns. The Parameter class represents the parameters of the manufacturing processes that have to be stored, such as the speed of the drill, the temperature, the water pressure, etc. 


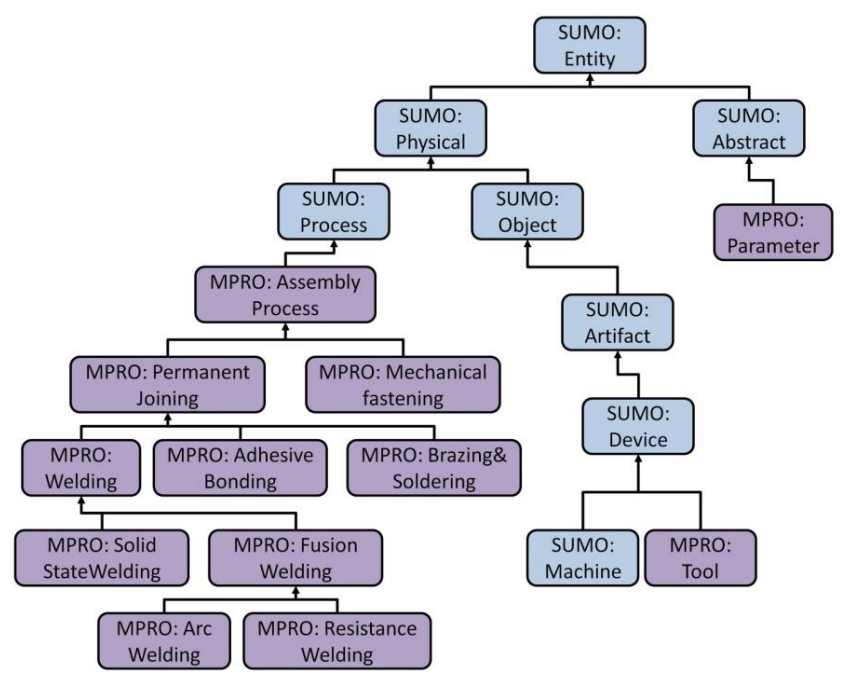

Fig. 4. Relationships between MPRO and SUMO concepts.

\section{Ontology-based HRC Cell Design}

The considered industrial process is the assembly of a two-stage cutter (shown in Fig.5 left), which is used to shred snow and send it to the rear turbine, which throws it out from the roadway. This process was originally executed manually by two operators, but the company wanted to evaluate the introduction of a robot to perform a subset of tasks. By mapping the industrial process on the MPRO ontology, we were able to define the processes and the corresponding tools that are needed in the cell, i.e., a welding torch for the arc welding and a grinder for the grinding process. These elements were inserted as instances of the corresponding entities in the ontology.

Assuming a task assignment was done (the assignment method is out of the scope of this work), by analysing the tasks assigned to the robot, and knowing that the kind of collaboration of interest in this case is a spatial collaboration, it was possible to exploit the CCORA ontology to select among the vast amount of possible kinds of robots, devices, etc., the set of elements needed in the cell. The following entities were considered: Industrial Robot, Observing device, Gripping device, and Holding device. Among the available industrial robots, the selection was for a KUKA robot KR 300 R2500 ultra C, due to the load and distance capacity. The holding devices are a tool plan to allow the robot executing the operations, a rotating platform so that the robot can easily reach all the positions required for the operations, and a component storage, where the final components are arranged according to a precise order in such a way that the robot can identify and pick them. The gripping device is a blocking gripper, so that the robot can move disks and spiders. The Observing devices are two laser scanners, one for verifying the correct positioning of tools and items, and another one to identify the human worker position. The resulting ontology corresponding to the HRC of such process is shown in Fig.5 (right). 

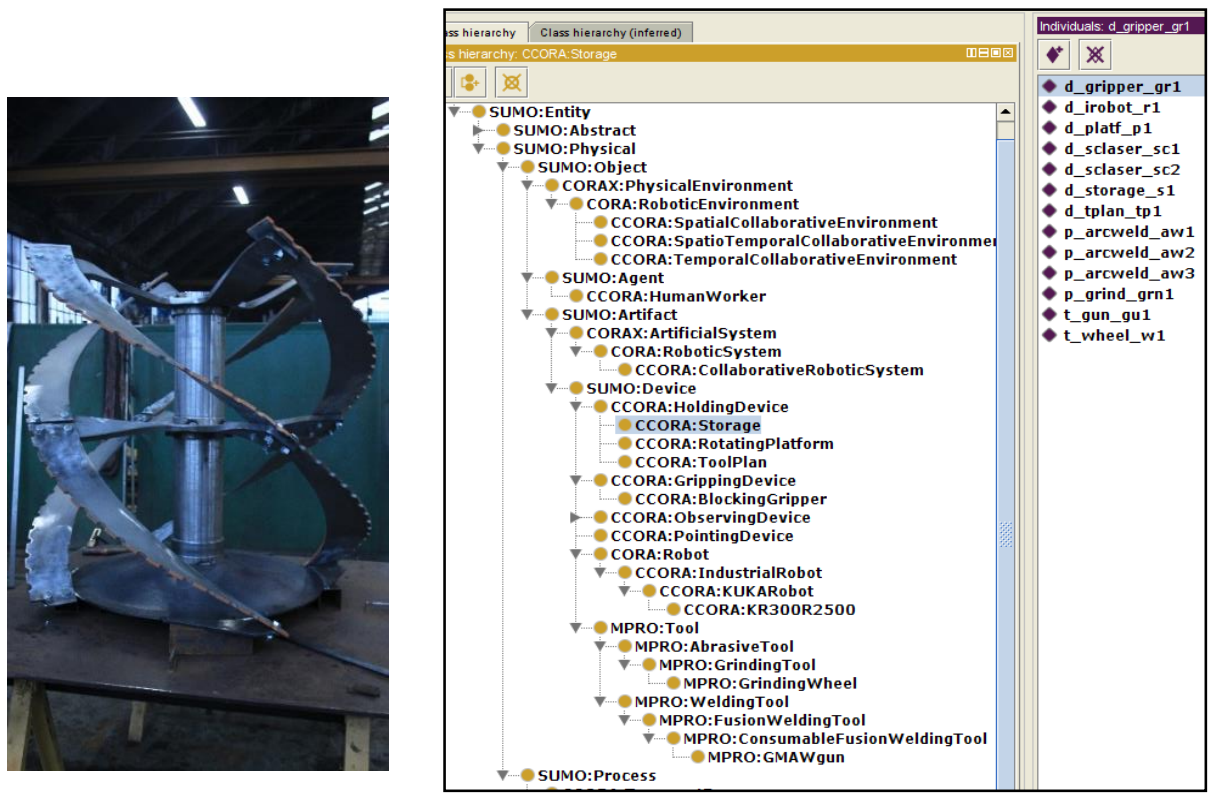

Fig. 5. Image of the cutter considered as use case (left) and the developed ontology with instances (right) shown in the Protégé (http://protege.stanford.edu)

\section{Conclusion}

The paper proposed a method to support the design of a human- robotic cell based on the industrial process of interest and the kind of HRC needed. Both the knowledge related to the machines and tools needed for the manufacturing process and the relationships between each kind of collaborative environment and the devices needed in the corresponding cell are stored in the ontology. From this knowledge base it is possible to select the elements needed for the full configuration of the cell.

\section{References}

1. Michalos, G., Makris, S., Papakostas, N., Mourtzis, D., \& Chryssolouris, G. (2010). Automotive assembly technologies review: challenges and outlook for a flexible and adaptive approach. CIRP Journal of Manufacturing Science and Technology, 2(2), 81-91

2. Helms, E., Schraft, R. D., \& Hagele, M. (2002).rob@ work: Robot assistant in industrial environments. In Robot and Human Interactive Communication, 2002. Proceedings. (pp. 399-404). IEEE.

3. Antonelli, D., Astanin, S., Bruno, G. (2016) Applicability of human-robot collaboration to small batch production, IFIP Advances in Information and Communication Technology, vol. 480, pp 24-32. 
4. Bischoff, R., et al. (2010). The KUKA-DLR Lightweight Robot arm-a new reference platform for robotics research and manufacturing. In Robotics (ISR), 201041 st international symposium. VDE.

5. Kirschner, D., Velik, R., Yahyanejad, S., Brandstötter, M., \& Hofbaur, M. (2016). YuMi, Come and Play with Me! A Collaborative Robot for Piecing Together a Tangram Puzzle. In International Conference on Interactive Collaborative Robotics (pp. 243-251). Springer.

6. Papakostas, N., Michalos, G., Makris, S., Zouzias, D., Chryssolouris, G. Industrial applications with cooperating robots for the flexible assembly, Int. J. Comput. Integr. Manuf., 24 (7), pp. 650-660 (2011)

7. Pedrocchi, N., Vicentini, F., Malosio, M., Tosatti, L.M. Safe human-robot cooperation in an industrial environment, Int. J. Adv. Robot. Syst., IJARS, 10 (27) (2012)

8. Harper, C., Virk, G. Towards the development of international safety standards for human robot interaction. Int. J. Social Robotics, 2(3), pp. 229-234 (2010)

9. Matthias, B. et al. Safety of collaborative industrial robots: Certification possibilities for a collaborative assembly robot concept. IEEE ISAM. (2011)

10. Ding, H., Schipper, M., Bjoern, M. Optimized task distribution for industrial assembly in mixed human-robot environments - case study on IO module assembly, IEEE International Conference on Automation Science and Engineering (2014)

11. Tan, J. T. C., Duan, F., Zhang, Y., \& Arai, T. (2009). Extending task analysis in HTA to model man-machine collaboration in cell production. In Robotics and Biomimetics, 2008. ROBIO 2008. IEEE International Conference on (pp. 542-547).

12. Hinds, P. J., Roberts, T. L., \& Jones, H. (2004). Whose job is it anyway? A study of human-robot interaction in a collaborative task. Human-Computer Interaction, 19(1), 151181

13. Freedy, A., DeVisser, E., Weltman, G., \& Coeyman, N. (2007). Measurement of trust in human-robot collaboration. In Collaborative Technologies and Systems, 2007. CTS 2007. International Symposium on (pp. 106-114). IEEE.

14. Argall, B.D., Chernova, S., Veloso, M., Browning, B. A survey of robot learning from demonstration. Robotics and Autonomous Systems 57(5), 469-483 (2009)

15. Antonelli, D., Astanin, S. (2016) Qualification of a collaborative human-robot welding cell, Procedia CIRP, 41, $352-357$.

16. Antonelli D, Astanin S, Caporaletti G, Donati F. (2014) FREE: Flexible and Safe Interactive Human-Robot Environment for Small Batch Exacting Applications. Gearing Accel. Cross-Fertil. Acad. Ind. Robot. Res. Eur., Springer, p. 47-62.

17. Bruno, G., Antonelli, D., Korf, R., Zimmermann, N. (2014) "Exploitation of a Semantic Platform to Store and Reuse PLM Knowledge" IFIP Advances in Information and Communication Technology, 438, pp. 59-66

18. Prestes E. et al. (2013) Towards a core ontology for robotics and automation, Robotics and Autonomous Systems, vol.61, 2013, pp.1193-1204.

19. Niles, I., Pease, A., (2001), Toward a Standard Upper Ontology, in Proceedings of the 2nd International Conference on Formal Ontology in Information Systems.

20. Fiorini, S.R. et al. (2015) Extensions to the core ontology for robotics and automation, Robotics and Computer-Integrated Manufacturing, vol. 33, pp.3-11.

21. Bruno, G. (2015) Semantic organization of product lifecycle information through a modular ontology, Int J of Circuits, Systems and Signal Processing, vol. 9, pp. 16-26. 